\title{
Practice Makes Perfect: Training Residents in Difficult Encounters
}

\author{
Jack Wells, MD, MHA | Nikole J. Cronk, PhD
}

PRiMER. 2020;4:2.

Published: 1/14/2020 | DOI: 10.22454/PRiMER.2020.924066

\section{Abstract}

Introduction: A significant number of patient encounters are perceived to be difficult. Residents receive little training in managing difficult clinical encounters, and lectures or traditional simulated patient encounters may not provide the opportunity to practice learned skills. Deliberate practice has been shown to be effective in training clinical skills. We used simulation with deliberate practice and feedback to train residents in difficult patient encounters.

Methods: Twelve second-year residents in the University of Missouri Family and Community Medicine residency program participated in simulated patient encounters with difficult patients. The patients represented challenging personalities identified in a resident focus group. Resident performance was scored by the standardized patient, resident observers, and faculty instructor. Following debriefing with feedback, the residents repeated the clinical encounter incorporating the feedback. The sessions were scored again by the same individuals.

Results: All scores improved from the first to second clinical encounter, except those that were at $100 \%$ for both encounters. The most improvement seen was in standardized patient scores. The smallest improvement was in provider self-scores.

Conclusion: Resident performance improved according to all observers and their own self-assessments. These results are consistent with other studies that have demonstrated the effectiveness of deliberate practice in improving skills in other areas of medical education. Simulation-based learning with deliberate practice has the potential to improve resident management of difficult patient encounters.

\section{Introduction}

Up to $15 \%$ of primary care encounters are perceived by providers to be difficult. ${ }^{1}$ Characteristics of these encounters include mental health issues, chronic pain, discordant expectations, and high utilization, among others. ${ }^{2}$ Providers, including residents, report frustration and feeling unprepared to adequately help these patients ${ }^{3-5}$ Residents receive little training in managing difficult clinical encounters, ${ }^{6}$ and didactic or traditional simulated patient encounters with feedback may not afford the opportunity to practice skills taught. ${ }^{7-9}$ Practice implementing constructive feedback is particularly salient for these draining and common clinical encounters. Deliberate practice is an educational technique allowing learners to practice using focused corrective feedback to achieve proficiency. ${ }^{10-11}$ Deliberate practice has not been well studied outside limited specialty and procedure realms, and its effectiveness with challenging patient encounters has not been documented. ${ }^{12}$ We used deliberate practice to train residents in difficult patient encounters. We hypothesized that learners would improve communication effectiveness and be more confident in these encounters following the training. 


\section{Methods}

Twelve second-year residents in the University of Missouri Family and Community Medicine residency program participated in training as part of a 2-week behavioral science immersion unit. Residents had expressed individually to faculty members their discomfort in managing difficult clinic patient encounters. They felt ill-prepared to manage patients who were demanding, angry, or abusive.

In order to better identify a potential training opportunity, the authors conducted a 15-minute focus group with 20 residents at all levels of training during a didactic session. They were asked what characteristics of patients they perceived to be challenging, what aspects of the encounter made the visit challenging, what skills they would like to have to better handle these encounters, and how to bring the visit to a mutually acceptable conclusion. The results of the focus group are shown in Table 1. The consensus of the group was that the most challenging patients were those perceived as seeking drugs, patients perceived to be nonadherent with recommended medical treatment, patients perceived to be resistant to recommended interventions, and patients perceived to be manipulative with hidden agendas.

Actors as standardized patients (SP) received training in portraying one of the four identified personality types prior to the session. Residents were assigned a prelearning PowerPoint module on a management strategy called LEARN, which we modified from other similar management techniques. ${ }^{13,14}$ LEARN emphasizes listening to the patient, empathizing with and acknowledging their concerns, responding appropriately, and planning next steps. We gave the residents were given a written test on the day of the session based on the prelearning material to ensure it was reviewed. They were then separated into four groups of three. Each group participated in three 10-minute clinical encounters, with one resident acting as clinician and the other two observing. Faculty members also observed the encounter. The encounters were scored by the SP, resident observers, faculty instructor, and self-scored by the resident clinician using a scoring instrument based on the prelearning material (Figure 1). This performance scoring instrument was a Likert scale developed by the authors to assess the faculty, resident, and learner perceptions of learner use of the LEARN techniques discussed in the prelearning PowerPoint. After the clinical encounter, debriefing with feedback and deliberate practice was done. The clinical encounter was then repeated incorporating the practice and feedback. The session was then rescored. Each group of three residents experienced three different encounters, allowing each resident to experience a patient encounter while the others observed (Table 2). After all rotations were completed, residents were instructed to select a patient from their own clinical practice and complete a Difficult Doctor Patient Questionnaire (DDPRQ) related to this patient immediately and again after their next clinical encounter with that patient. The DDPRQ is a validated instrument shown to effectively measure the perceived degree of difficulty in doctor-patient interactions (DDPRQ 15). Residents were asked to provide feedback on the training experience. Our institutional review board classified this project as a quality improvement activity not requiring review.

\section{Results}

All 12 residents (seven male, five female) completed the prelearning test successfully to begin the deliberate practice sessions (median=94.1\%; range $=82.3 \%-100 \%$ ). We examined scores on the encounter scoring instrument as a percentage of the total, and they could range from $0 \%$ to $100 \%$. The percent scores of each resident were compared between the first and second encounter to determine changes in performance. All scores improved from the first to second clinical encounter, except those ( $n=2$ self-assessment; $n=3$ faculty and peer assessment) that were at $100 \%$ for both encounters (Table 3 ). The most improvement seen was in SP scores. The smallest improvement was in provider self-assessment scores. Resident feedback evaluating the encounter was largely positive (Table 4). Overall, five learners felt the session was valuable, one thought it was maybe valuable, and five did not answer. Feedback was mixed regarding the likelihood of affecting practice patterns, with four residents reporting they thought it would, and three reporting maybe (five did not answer). The most frequent positive comments were appreciative of the feedback and ability to observe other residents. The most frequent negative comment was that SPs were "too nice" and not as aggressive as anticipated. 
Scores on the DDPRQ could range from 0 to 180, with higher scores indicating greater perceived relationship difficulty. The mean score for residents immediately following the simulated encounter was 113.67 (SD 18.19) with a range of 97-150. Nine residents returned the follow-up DDPRQ after seeing the identified patient in their clinics between 33 and 113 days postsimulated encounter. There was a mean overall decrease in scores (79.66; SD 51.51). Of the nine residents, five had lower DDPRQ scores after seeing their patient, and four had higher scores (Figure 2). The length of time between the simulated encounter and seeing the patient in clinic was not associated with change in DDPRQ scores $(r=-0.23)$.

\section{Conclusions}

This study examined the feasibility and effectiveness of using simulated encounters with deliberate practice to help residents more effectively manage difficult patient encounters. Results from a focus group indicated that residents identify particular patients as challenging and were able to articulate the characteristics of those patients that cause them the most stress. These patient encounters, while stressful, have not systematically been addressed in the residency curriculum. If training is done, it is often in the form of role play or observing a scenario. ${ }^{16,17}$ Residents are rarely given the opportunity to participate in a patient encounter, practice techniques based on feedback, and then repeat the encounter incorporating that feedback.

This technique allows learners to practice correct techniques. They receive feedback after an ineffective encounter, practice a correct encounter, and experience the difference. Residents were receptive to the training and identified feedback and peer observation as particularly useful. Resident evaluations indicated that deliberate practice in managing difficult patient encounters was helpful and resulted in performance improvement in this session. These results support the importance of focusing attention on challenging encounters that residents have heretofore dealt with in isolation or with limited feedback about performance. These findings are consistent with studies demonstrating the effectiveness of deliberate practice in improving skills with other aspects of clinical medicine, including performing procedures. ${ }^{18-21}$ Various techniques used in training providers to manage difficult patient encounters have been documented, ${ }^{22-24}$ however to our knowledge this is the first study to examine the effectiveness of utilizing deliberate practice in this context.

It is not clear why some residents' ratings of the difficulty of working with a self-identified patient in their continuity clinics decreased while others increased. Likely contributing factors include the low number of resident responses, and that only two patient encounters were scored with the DDPRQ. Trends in perceived difficulty of working with particular patients may take longer to emerge, and two data points may be insufficient to identify changes. Another possible explanation could be that the length of time between the last patient encounter prior to the simulated encounter and the simulated encounter itself skewed perceptions of the difficulty of working with that patient.

The value of this experience for residents is also evidenced by their desire to have yet more difficult simulations as indicated in the postexperience feedback. Residents noted that the simulated patients were not challenging enough, which may have made the intervention less than maximally effective. This does, however, support the receptiveness of residents to engaging in deliberate practice with the encounters they identify as most challenging. Future encounters will include increasingly difficult patient behaviors. Additionally, there may be value in having booster sessions to prevent decay of skills developed in the encounter. Limitations of the study include the small sample size and residents' perceptions of the encounters. We feel simulation-based learning with deliberate practice has the potential to help residents learn to better manage difficult patient encounters.

\section{Tables and Figures}


Table 1: Results of Focus Group Regarding Challenging Patient Encounters

\begin{tabular}{|l|l|}
\hline \multicolumn{1}{|c|}{ Questions Asked to Residents } & \multicolumn{1}{c|}{ Resident Responses } \\
\hline \multirow{2}{*}{ What patient behaviors or issues do you find challenging? } & $\begin{array}{l}\text { Unrealistic expectations } \\
\text { Verbally combative } \\
\text { Demanding } \\
\text { Defined agenda } \\
\text { Noncompliant } \\
\text { No faith in the plan-bad attitude } \\
\text { Unmet needs: mental health, language barrier, chronic pain }\end{array}$ \\
\begin{tabular}{ll} 
Things that slow you down \\
\hline \multirow{2}{*}{ What makes those issues challenging? }
\end{tabular} & $\begin{array}{l}\text { Patient's anger and frustration make the provider uncomfortable } \\
\text { Patient not listening; provider feels unheard } \\
\text { Patient anger-walking out } \\
\text { Unrealistic expectations }\end{array}$ \\
$\begin{array}{l}\text { When patient doesn't listen, the provider tends to shut down; we } \\
\text { want to help. } \\
\text { Worry about patient satisfaction scores }\end{array}$ \\
\hline \multirow{2}{*}{ What skills would you like to gain? } & $\begin{array}{l}\text { Ability to control the encounter } \\
\text { Ability to control personal feelings about the patient } \\
\text { Separate the patient from the situation. }\end{array}$ \\
& $\begin{array}{l}\text { Learn how to "give in" a little } \\
\text { Ability to say no }\end{array}$ \\
\hline
\end{tabular}

Figure 1: Performance Scoring Instrument

1. To what extent did you feel the provider listened to the patient during this encounter?

\begin{tabular}{|ccccc|}
\hline $\begin{array}{c}1 \\
\text { Not at all }\end{array}$ & 2 & 3 & 4 & $\begin{array}{c}5 \\
\text { Very much }\end{array}$ \\
\hline
\end{tabular}

2. To what extent did you feel that the provider showed empathy for the patient and their situation?

\begin{tabular}{|ccccc|}
\hline $\begin{array}{c}1 \\
\text { Not at all }\end{array}$ & 2 & 3 & 4 & $\begin{array}{c}5 \\
\text { Very much }\end{array}$ \\
\hline
\end{tabular}

3. To what extent did you feel the provider acknowledged the patient's feelings and perspective?

\begin{tabular}{|ccccc|}
\hline $\begin{array}{c}1 \\
\text { Not at all }\end{array}$ & 2 & 3 & 4 & 5 \\
Very much
\end{tabular}

4. To what extent did you feel the provider responded to the patient in a professional and appropriate manner?

\begin{tabular}{|ccccc|}
\hline $\begin{array}{c}1 \\
\text { Not at all }\end{array}$ & 2 & 3 & 4 & $\begin{array}{c}5 \\
\text { Very much }\end{array}$ \\
\hline
\end{tabular}

5. To what extent did you feel the provider communicated next steps in the treatment plan?

\begin{tabular}{|ccccc|}
\hline $\begin{array}{c}1 \\
\text { Not at all }\end{array}$ & 2 & 3 & 4 & 5 \\
Very much
\end{tabular}


Table 2: Timeline of Difficult Patient Encounter Project

\begin{tabular}{|c|c|c|c|c|c|c|}
\hline April 3 & \multicolumn{6}{|c|}{ Focus group of difficult patient perceptions with residents $(N=20)$} \\
\hline March-July & \multicolumn{6}{|c|}{$\begin{array}{l}\text { Difficult patient simulated cases written and actors trained } \\
\text { Prelearning PowerPoint generated and sent to residents } 1 \text { week prior to the session }\end{array}$} \\
\hline \multicolumn{7}{|l|}{ July 26} \\
\hline \multirow[t]{2}{*}{$15 \mathrm{~min}$} & \multicolumn{6}{|c|}{ Postlearning assessment administered } \\
\hline & & & Case A & Case B & Case C & Case D \\
\hline \multirow[t]{2}{*}{$10 \mathrm{~min}$} & Encounter 1 & Provider: & Resident 1 & Resident 4 & Resident 7 & Resident 10 \\
\hline & & Observers: & Residents 2,3 & Residents 5,6 & Residents 8,9 & Residents 11,12 \\
\hline $10 \mathrm{~min}$ & & \multicolumn{5}{|c|}{ Debrief \& Feedback on Encounter 1} \\
\hline \multirow[t]{2}{*}{$10 \mathrm{~min}$} & Encounter 2 & Provider: & Resident 1 & Resident 4 & Resident 7 & Resident 10 \\
\hline & & Observers: & Residents 2,3 & Residents 5,6 & Residents 8,9 & Residents 11,12 \\
\hline $10 \mathrm{~min}$ & & \multicolumn{5}{|c|}{ Debrief and Feedback on Encounter 2} \\
\hline \multirow[t]{2}{*}{$10 \mathrm{~min}$} & Encounter 1 & Provider: & Resident 11 & Resident 2 & Resident 5 & Resident 8 \\
\hline & & Observers: & Residents 10,12 & Residents 1,3 & Residents 4,6 & Residents 7,9 \\
\hline $10 \mathrm{~min}$ & & \multicolumn{5}{|c|}{ Debrief and Feedback on Encounter 1} \\
\hline \multirow[t]{2}{*}{$10 \mathrm{~min}$} & Encounter 2 & Provider: & Resident 11 & Resident 2 & Resident 5 & Resident 8 \\
\hline & & Observers: & Residents 10,12 & Residents 1,3 & Residents 4,6 & Residents 7,9 \\
\hline $10 \mathrm{~min}$ & & \multicolumn{5}{|c|}{ Debrief and Feedback on Encounter 2} \\
\hline \multirow[t]{2}{*}{$10 \mathrm{~min}$} & Encounter 1 & Provider: & Resident 9 & Resident 12 & Resident 3 & Resident 6 \\
\hline & & Observers: & Residents 7,8 & Residents 10,11 & Residents 1,2 & Residents 4,5 \\
\hline $10 \mathrm{~min}$ & & \multicolumn{5}{|c|}{ Debrief and Feedback on Encounter 1} \\
\hline \multirow[t]{2}{*}{$10 \mathrm{~min}$} & Encounter 2 & Provider: & Resident 9 & Resident 12 & Resident 3 & Resident 6 \\
\hline & & Observers: & Residents 7,8 & Residents 10,11 & Residents 1,2 & Residents 4,5 \\
\hline $10 \mathrm{~min}$ & & \multicolumn{5}{|c|}{ Debrief and Feedback on Encounter 2} \\
\hline $15 \mathrm{~min}$ & & \multicolumn{5}{|c|}{ DDPRQ and session evaluation administered } \\
\hline Aug-Dec & & \multicolumn{5}{|c|}{ Follow-up DDPRQ completed after patient seen in clinic } \\
\hline
\end{tabular}

Abbreviation: DDPRQ, Difficult Doctor-Patient Relationship Questionnaire.

Table 3: Median Performance Scores

\begin{tabular}{|c|c|c|c|}
\hline Rater & First Encounter & Second Encounter & Difference (\%) \\
\hline Faculty & 72 & 90 & 18 \\
\hline Peer & 91 & 99 & 8 \\
\hline Self & 80 & 88 & 8 \\
\hline SP & 80.5 & 96 & 15.5 \\
\hline
\end{tabular}

Scores are percentages of possible points and could range from 0-100.

Abbreviation: SP, simulated patient. 
Table 4: Selected Resident Feedback Regarding the Simulated Experience

\begin{tabular}{|l|}
\hline \multicolumn{1}{|c|}{ What Went Well } \\
\hline Able to observe peers interact with patients \\
\hline Organization, the actors, practice \\
\hline Feel like I learned more from seeing how my colleagues go about these simulations than actually doing it \\
\hline Specific feedback \\
\hline Great feedback from SP and colleagues \\
\hline Feedback after each encounter. Observing what my colleagues do and applying their strategies \\
\hline \\
\hline More realistic patients. SP too kind-never raised their voices or demanded meds which is what I truly have difficulty with in clinic \\
\hline More difficult patient encounters \\
\hline More chronic pain, have patients be more resistant, some were actually too nice \\
\hline Allowing some choice in difficult encounter \\
\hline Having patients be less agreeable to therapy, clear instructions of encounter \\
\hline Have SP debrief after second encounter \\
\hline
\end{tabular}

Abbreviation: SP, simulated patient.

Figure 2: Difficult Doctor-Patient Relationship Questionnaire (DDPRQ) Scores

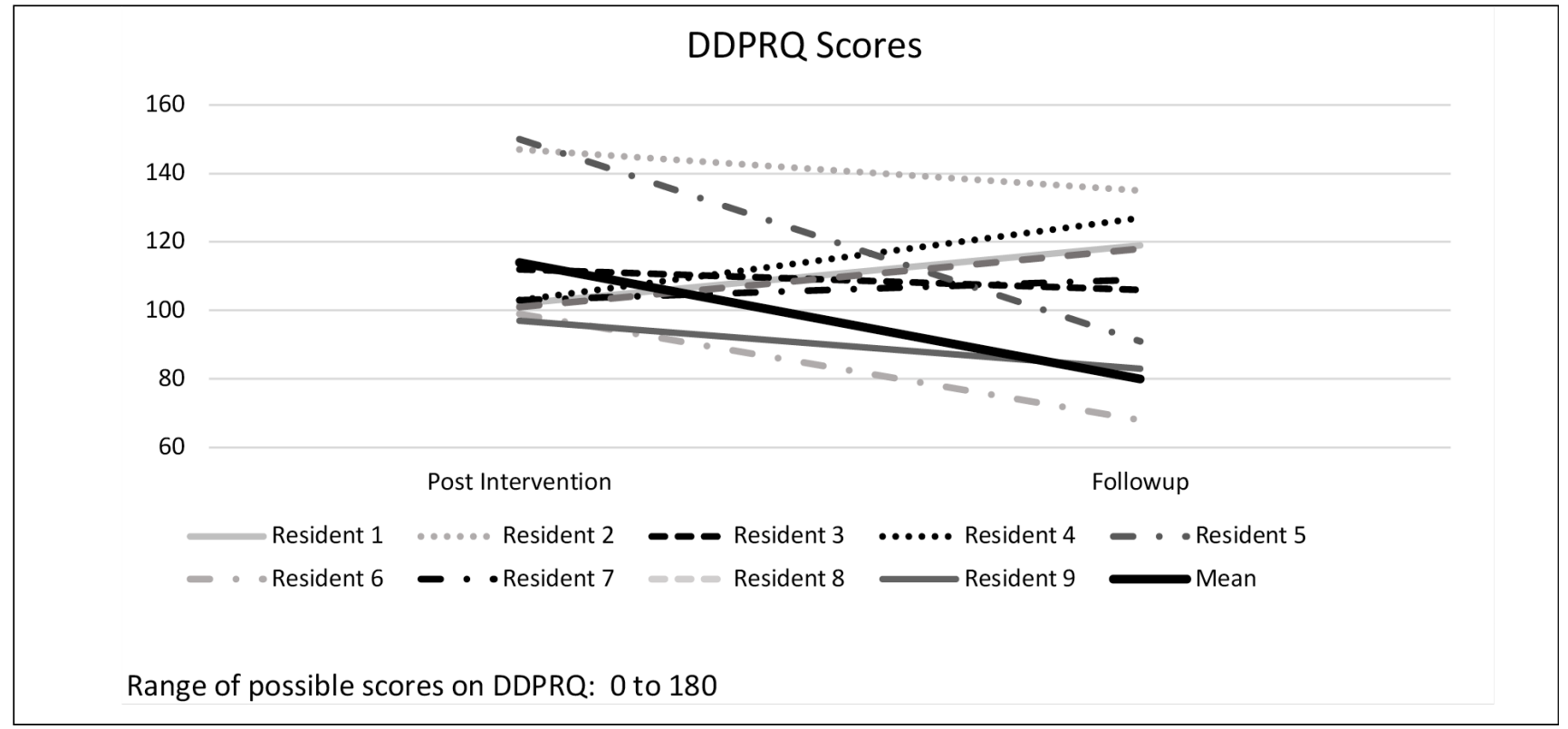

\section{Acknowledgments}

Presentation: Practice Makes Perfect: Using Simulation, Feedback, and Practice to Train Family Medicine Residents in Difficult Patient Encounters. January 28, 2019. International meeting for Simulation in Healthcare (IMSH), San Antonio, TX.

\section{Corresponding Author}

Jack Wells, MD, MHA

M245 Medical Sciences Building, Department of Family and Community Medicine, School of Medicine, University of Missouri, Columbia, MO 65212. 573-999-6502. Fax: 573-642-3015.

wellsjack@health.missouri.edu 


\section{Author Affiliations}

Jack Wells, MD, MHA - Department of Family and Community Medicine, School of Medicine, University of Missouri, Columbia, MO

Nikole J. Cronk, PhD - University of Missouri School of Medicine, Department of Family and Community Medicine, Columbia, MO

\section{References}

1. Hinchey SA, Jackson JL. A cohort study assessing difficult patient encounters in a walk-in primary care clinic, predictors and outcomes. J Gen Intern Med. 2011;26(6):588-594. https://doi.org/10.1007/s11606-010-1620-6

2. Cannarella Lorenzetti R, Jacques $\mathrm{CH}$, Donovan $\mathrm{C}$, Cottrell S, Buck J. Managing difficult encounters: understanding physician, patient, and situational factors. Am Fam Physician. 2013;87(6):419-425.

3. Shapiro J, Lie D. Using literature to help physician-learners understand and manage "difficult" patients. Acad Med. 2000;75(7):765-768. https://doi.org/10.1097/00001888-200007000-00026

4. Krebs EE, Garrett JM, Konrad TR. The difficult doctor? Characteristics of physicians who report frustration with patients: an analysis of survey data. BMC Health Serv Res. 2006;6(1):128. https://doi.org/10.1186 /1472-6963-6-128

5. Fenton JJ, Franks P, Feldman MD, et al. Impact of patient requests on provider-perceived visit difficulty in primary care. J Gen Intern Med. 2015;30(2):214-220. https://doi.org/10.1007/s11606-014-3082-8

6. Didden DG, Philbrick JT, Schorling JB. Anxiety and depression in an internal medicine resident continuity clinic: difficult diagnoses. Int J Psychiatry Med. 2001;31(2):155-167. https://doi.org/10.2190/C7WYRELT-3U1N-JX9C

7. Simmons L, Leavitt L, Ray A, Fosburgh B, Sepucha K. Shared decision making in common chronic conditions: impact of a resident training workshop. Teach Learn Med. 2016;28(2):202-209. https://doi.org/10.1080 /10401334.2016.1146600

8. Eppich W, Hunt E. Duval -Arnould JM, Jo Siddal V, Cheng A. Structured feedback and debriefing to achieve mastery learning goals. Acad Med. 2015;90:1501-1508. https://doi.org/10.1097/ACM.0000000000000934

9. Cory MJ, Colman N, McCracken CE, Hebbar KB. Rapid cycle deliberate practice verses reflective debriefing for pediatric septic shock training. Pediatr Crit Care Med. 2019;20(5):481-489. https://doi.org/10.1097 /PCC.0000000000001891

10. Fanning RM, Gaba DM. The role of debriefing in simulation-based learning. Simul Healthc. 2007;2(2):115-125. https://doi.org/10.1097/SIH.0b013e3180315539

11. Ericsson KA. Acquisition and maintenance of medical expertise: a perspective from the expert-performance approach with deliberate practice. Acad Med. 2015;90(11):1471-1486. https://doi.org/10.1097 /ACM.0000000000000939

12. Taras J, Everett $\mathrm{T}$. Rapid cycle deliberate practice in medical education - a systematic review. Cureus. 2017;9(4):e1180. https://doi.org/10.7759/cureus.1180

13. Edgoose JY, Regner CJ, Zakletskaia LI. BREATHE OUT: a randomized controlled trial of a structured intervention to improve clinician satisfaction with "difficult" visits. J Am Board Fam Med. 2015;28(1):13-20. https://doi.org/10.3122/jabfm.2015.01.130323

14. Kane M, Chambliss ML. Getting to no: how to respond to inappropriate patient requests. Fam Pract Manag. 2018;25(1):25-30.

15. Hahn SR, Thompson KS, Wills TA, Stern V, Budner NS. The difficult doctor-patient relationship: somatization, personality and psychopathology. J Clin Epidemiol. 1994;47(6):647-657. https://doi.org/10.1016 /0895-4356(94)90212-7

16. Zubatsky M, Brieler J, Jacobs $C$. Training experiences of family medicine residents on behavioral health rotations. Fam Med. 2017;49(8):635-639.

17. Oshman LD, Combs GN. Integrating motivational interviewing and narrative therapy to teach behavior change to family medicine resident physicians. Int J Psychiatry Med. 2016;51(4):367-378. https://doi.org/10.1177 /0091217416659273

18. Kilbane BJ, Adler MD, Trainor JL. Pediatric residents' ability to perform a lumbar puncture: evaluation of an 
educational intervention. Pediatr Emerg Care. 2010;26(8):558-562. https://doi.org/10.1097

/PEC.0b013e3181ea720d

19. Barsuk JH, McGaghie WC, Cohen ER, Balachandran JS, Wayne DB. Use of simulation-based mastery learning to improve the quality of central venous catheter placement in a medical intensive care unit. $\mathrm{J}$ Hosp Med. 2009;4(7):397-403. https://doi.org/10.1002/jhm.468

20. McGaghie WC, Issenberg SB, Cohen ER, Barsuk JH, Wayne DB. Does simulation-based medical education with deliberate practice yield better results than traditional clinical education? A meta-analytic comparative review of the evidence. Acad Med. 2011;86(6):706-711. https://doi.org/10.1097/ACM.0b013e318217e119

21. McGaghie WC, Issenberg SB, Barsuk JH, Wayne DB. A critical review of simulation-based mastery learning with translational outcomes. Med Educ. 2014;48(4):375-385. https://doi.org/10.1111/medu.12391

22. Elder N, Ricer R, Tobias B. How respected family physicians manage difficult patient encounters. J Am Board Fam Med. 2006;19(6):533-541. https://doi.org/10.3122/jabfm.19.6.533

23. An PG, Manwell LB, Williams ES, et al. Does a higher frequency of difficult patient encounters lead to lower quality care? J Fam Pract. 2013;62(1):24-29. PMID:23326819

24. Smith CD. A curriculum to address family medicine residents' skills in treating patients with chronic pain. Int $J$ Psychiatry Med. 2014;47(4):327-336. https://doi.org/10.2190/PM.47.4.g

Copyright $(2020$ by the Society of Teachers of Family Medicine 